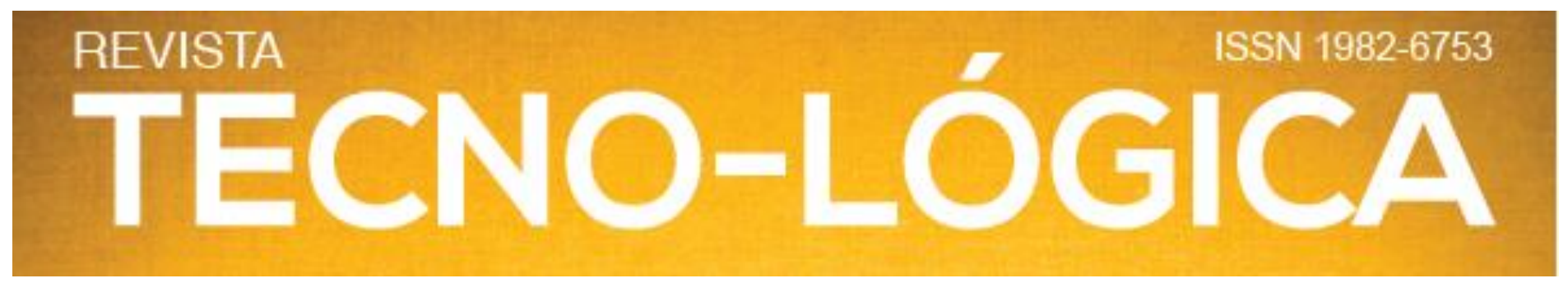

\title{
APLICAÇÃo DE MODELOS DE PREVISÃo E INTELIGÊNCIA ARTIFICIAL PARA AVALIAR DEMANDA NO SEGMENTO DE SISTEMAS DE ILUMINAÇÃO AUTOMOTIVO
}

\author{
José Luiz Carrer Torres* , Leandro Luís Corso

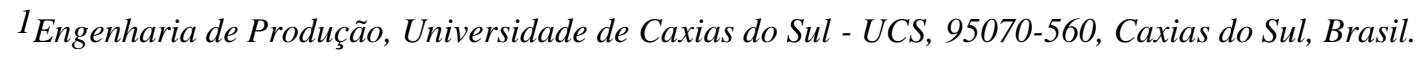

*E-mail: jl-torres@hotmail.com

Recebido em:02/04/2021

Aceito em:07/06/2021

DOI:10.17058/tecnolog.v25i2.16425

\section{RESUMO}

A concorrência de mercado estimula as organizações a buscarem inovações, com o objetivo de alcançarem posição de destaque, trazendo diferenciais para o segmento em que atuam. Essa competitividade severa faz com que, também, seja necessário às empresas procurar formas de redução de custos, otimização de processos; a acuracidade na previsão de demanda é fator essencial para o aprimoramento da produtividade, a gestão de estoque, a redução de lead time, contribuindo para a melhora dos resultados da empresa. Este trabalho tem como objetivo utilizar modelos matemáticos de séries temporais e inteligência artificial para verificar qual método possui maior acuracidade nas previsões de demanda dos principais produtos de uma organização do segmento de sistemas de iluminação automotivo. Para o método de Redes Neurais Artificiais (RNA), buscou-se otimizá-lo, utilizando-se configurações em relação ao número de neurônios e diferentes algoritmos de treinamento para encontrar os modelos mais assertivos. Por meio da aplicação dos erros de previsão MAPE e MAE, constatou-se que determinadas configurações de RNA são os métodos de melhor acuracidade para realização das previsões dos produtos analisados, em que foi possível concluir que, em média, os erros de previsão da RNA otimizada são de 3,25 vezes (para o MAPE) e de 4 vezes (para o MAE) menor em relação ao método atual da empresa.

Palavras-chave: Previsão de demanda. Gestão de estoque. Redes Neurais Artificiais.

\section{Introdução}

A competitividade econômica global faz com que as empresas invistam em tecnologias e inovações, visando adquirir diferenciais que as coloquem em posições relevantes no mercado [1]. Além de buscar a inovação, visar reduzir custos operacionais, logísticos, realizar melhorias e otimizar processos, são situações essenciais para que as organizações se mantenham economicamente saudáveis. Segundo Mancuso e Werner [2], diante desse cenário, faz-se necessário, também, utilizar métodos de previsão de demanda que sejam eficazes, que resultem em informações mais próximas possíveis do que virá de fato acontecer, tendo em vista que afetará diretamente a lucratividade da organização.

Atualmente, há diversos métodos de previsões de demanda e, devido ao fato de haver comportamentos diferentes de dados, faz-se necessária a aplicação de modelos diversificados. O conceito Auto Regressivo Integrado de Médias Móveis (ARIMA) é o mais conhecido para modelos de séries temporais estocásticas. Nos últimos anos, técnicas de Inteligência Artificial (IA) estão sendo utilizadas com mais frequência, devido à alta acurácia encontrada em inúmeros casos, as quais buscam implementar modelos matemáticos que representam as estruturas neurais humanas. As Redes Neurais Artificiais, uma das principais técnicas de IA, são elaboradas para modelar o modo como se executa uma tarefa específica ou função de interesse, se assemelhando ao cérebro humano por meio do conhecimento que é adquirido pela rede a partir de seu ambiente através de um processo de aprendizagem e pelas forças de conexão entre neurônios, chamados de pesos sinápticos, os quais são usados para armazenar o conhecimento adquirido [3].

Procedimentos de suavização exponencial também são utilizados com constância nas previsões de vendas, a exemplo do método de Holt Winters, o qual é simples, rápido e acessível [4]. De uma forma geral, sabe-se que métodos de previsões de demanda podem auxiliar em diversas estratégias das organizações, como gerenciar e otimizar operações, desenvolver um gerenciamento de demanda ideal e eficaz, fornecer estimativas de picos ou vales de demandas [5]. 


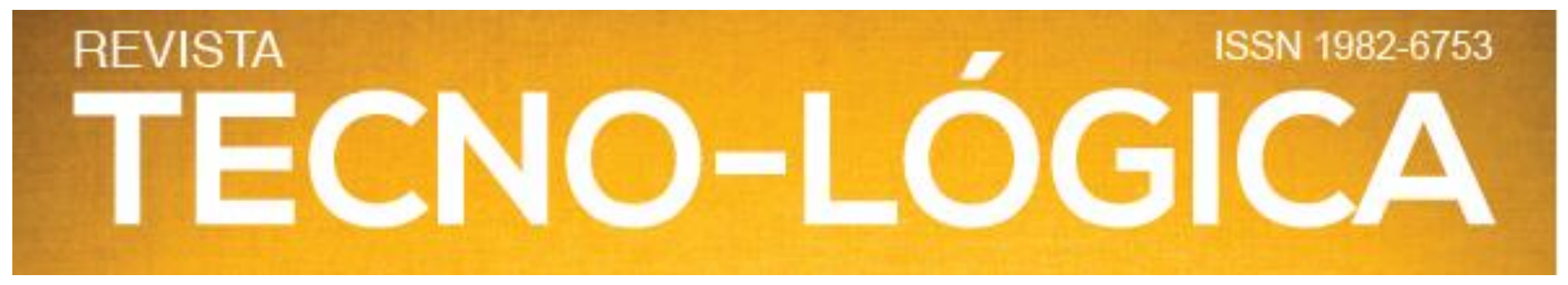

Os modelos de previsões utilizam históricos de informações, quanto maior o período de análise, maior tende ser a acuracidade para prever os valores futuros [6]. Vale ressaltar que os conceitos de previsão de demanda não são válidos apenas para a área industrial, tendo em vista que empresas prestadoras de serviços também necessitam de organização e planejamento. A acurácia na previsão de demanda no setor de serviços é relevante, pois a organização pode utilizar a informação para dimensionar a capacidade [7].

No presente artigo, realizou-se um comparativo de acuracidade entre métodos de previsão de demanda em uma empresa de sistemas de iluminação e elétrico para a linha automotiva pesada (ônibus, implementos rodoviários e agrícolas); o fator principal que justificou a realização deste trabalho é a variação considerável de demanda ao longo do período, situação decorrente, principalmente, das oscilações de mercado e influências político-econômicas. $\mathrm{O}$ foco das previsões foi para as lanternas traseiras que a empresa produz, sendo essa linha a principal do portfólio da organização. Coletou-se o histórico de vendas, em um período de 36 meses, dos quatro principais modelos de lanternas traseiras, os quais são fornecidos, exclusivamente, para as maiores implementadoras rodoviárias que a empresa atende. Em relação aos meios de previsão de demanda, foram utilizados Média Móvel Ponderada, Holt Winters Aditivo e Multiplicativo, ARIMA e RNA.

$\mathrm{O}$ artigo foi seccionado contemplando referencial teórico, em que se descreve os conceitos utilizados no estudo; metodologia, em que são citados os procedimentos para realização do trabalho; desenvolvimento, apresentando os resultados obtidos e as considerações finais que foram possíveis alcançar por meio da elaboração do trabalho.

\section{Referencial Teórico}

Nesta seção é elucidado, de forma breve, as definições de Gestão de Estoque e Previsão de Demanda, além de descrever os conceitos dos modelos matemáticos utilizados, bem como, os métodos de erros de previsão para avaliar o desempenho e a acuracidade dos modelos.

\subsection{Gestão de Estoque}

A gestão de estoque é crucial nas organizações, tendo como princípio básico o objetivo de manter níveis baixos de matériasprimas ou produtos prontos, equalizando seus custos e, paralelamente, possuindo um nível adequado para suprimento da demanda [8]. De acordo com [9], o estoque apenas é desperdício quando possui por finalidade atender as deficiências operacionais organizacionais ou é gerado pela defasagem entre a demanda e a previsão.

O nível de estoque de segurança se modifica conforme a oscilação das divergências entre o que foi previsto e o que é realmente demandado. A otimização dos estoques acontece quando se produz exatamente o que é necessário e obtém-se um fluxo de demanda sem oscilações.

\subsection{Previsão de Demanda}

Previsão de demanda é a atividade de mensurar a quantia de um produto ou serviço que será necessária adquirir para atender determinado período a um preço específico. A análise da demanda envolve técnicas que incluem métodos informais (estimativas subjetivas) e modelos quantitativos (uso de dados históricos ou dados atuais de consumo e produção) [10].

Técnicas quantitativas possuem dois segmentos de estudo, sendo os modelos causais e as análises de séries temporais. As análises das séries temporais usam como base os dados históricos de demanda, adotando tendências e padrões sazonais, que, ao serem extrapolados, ajudam a mensurar o futuro. Os métodos causais utilizam informações históricas para variáveis dependentes e independentes, buscando relações de similaridade entre situações que influenciam a procura de um produto ou serviço [11].

Como exemplos de modelos de séries temporais, cita-se a Suavização Exponencial (Holt Winters), Média Móvel e ARIMA. Já como aplicações de técnicas causais, há a Regressão Linear, Regressão Múltipla e Inteligência Artificial [12].

\subsubsection{Média Móvel Ponderada (MMP)}

A MMP utiliza os dados históricos para a projeção futura. Tem como característica principal valorizar com mais relevância as informações mais recentes [13]. A soma da ponderação dos pesos, dado a cada período, deve ser igual a 1 . O cálculo para obtenção da MMP pode ser realizado conforme segue a Equação 1.

$P(M M P)=\frac{\sum_{t=1}^{n} W_{t-1} S_{t-1}}{\sum W_{t}}$

Em que $W_{t-1}$ são os pesos dados a cada período, $S_{t-1}$ o histórico de vendas do período e $n$ a quantia total de intervalos de tempo. 


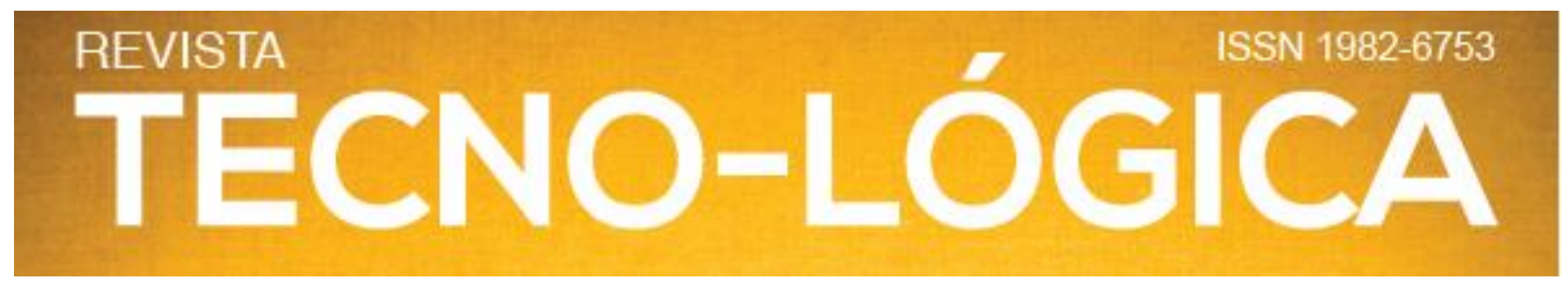

\subsubsection{Holt Winters Aditivo (HWA) e Multiplicativo (HWM)}

O método de suavização exponencial de Holt Winters é mais comumente utilizado quando há tendência e sazonalidade na série de dados. Esse modelo possui como base três equações de suavização: por nível, por tendência e por sazonalidade [14].

A escolha pelo uso do HWA ou HWM para realização da previsão depende das características da série analisada, visto que o método aditivo é usado quando a variável sazonal é constante e o método multiplicativo é indicado quando a variação sazonal diminui ou aumenta ao longo do tempo [15].

A respeito do método HWM, as fórmulas para verificação de nível, tendência, sazonalidade e previsão seguem de acordo com as Equações 2, 3, 4 e 5, respectivamente.

$N_{t}=\alpha\left(\frac{Y_{t}}{S_{t-s}}\right)+(1-\alpha)\left(N_{t-1}+T_{t-1}\right)$

$T_{t}=\beta\left(N_{t}-N_{t-1}\right)+(1-\beta) T_{t-1}$

$S_{t}=\gamma\left(\frac{Y_{t}}{N_{t}}\right)+(1-\gamma) S_{t-s}$

$P_{t+m}=\left(N_{t}+T_{t} m\right) S_{t-s+m}$

Em que $\alpha, \beta, \gamma$ são parâmetros de suavização (que devem estar em um intervalo de 0 a 1 ), m é o número de previsões futuras, $\mathrm{s}$ é o tempo de sazonalidade (por exemplo, número de meses ou trimestres em um ano), $Y_{t}$ são os dados observados no momento t, $N_{t}$ diz respeito ao nível referente ao tempo t analisado, $T_{t}$ é a tendência no momento $\mathrm{t}$ e $P_{t}$ é a previsão no período t. Inicialmente para o nível, define-se $N_{s}=\frac{\left(Y_{1}+Y_{2}+\cdots+Y_{S}\right)}{\mathrm{s}}$, sendo, neste estudo, $\mathrm{s}=12$ meses; em relação à tendência, utiliza-se $T_{s}=$ $\frac{\left(Y_{s}+1-Y_{1}\right)}{\mathrm{s}}$ e para as variáveis sazonais calcula-se $S_{p}=\frac{Y_{p}}{N_{s}}$, em que $\mathrm{p}=1,2,3, \ldots, 12[16]$.

Para implementação do método HWA, devem-se utilizar as Equações 6, 7, 8 e 9 para definição do nível, tendência, sazonalidade e previsão de demanda, respectivamente.

$N_{t}=\alpha\left(Y_{t}-S_{t-s}\right)+(1-\alpha)\left(N_{t-1}+T_{t-1}\right)$

$T_{t}=\beta\left(N_{t}-N_{t-1}\right)+(1-\beta) T_{t-1}$

$S_{t}=\gamma\left(Y_{t}-N_{t}\right)+(1-\gamma) S_{t-s}$

$P_{t+m}=N_{t}+T_{t} m+S_{t-s+m}$

A Equação 7 é exatamente igual à Equação 3 do método HWM; basicamente, o que altera de um modelo para o outro é que no modelo HWA as variáveis sazonais são adicionadas ou subtraídas, em vez de serem multiplicadas ou divididas como no HWM. Os valores iniciais de nível e tendência para o HWA são os mesmos que no HWM. Já em relação às variáveis sazonais, deve-se usar $S_{p}=Y_{p}-N_{s}$.

\subsubsection{Autorregressivo Integrado de Médias Móveis (ARIMA)}

O método ARIMA é também conhecido como método de Box-Jenkins; esse modelo visa assimilar o comportamento da correlação seriada ou verificar a semelhança entre os valores de uma série de tempo e, conforme o comportamento desses valores, determinar demandas futuras. Especificamente, o modelo ARIMA originou-se com o intuito de ser implementado em análises de dados temporais com padrão forte de sazonalidade [17].

É comum determinadas séries temporais não serem estacionárias, ou seja, são integradas. Contudo, quando a série não é estacionária, ela sofre modificações para se tornar estacionária a partir do processo de diferenciação de dados. O modelo ARIMA foi concebido por meio dos métodos de autorregressão (AR), do termo de integração (I) e das médias móveis (MA), além da combinação entre os modelos AR e MA (modelo ARMA) [18].

Logo, a série temporal será representada por ARIMA $(p, d$, $q$ ), sendo $\mathrm{p}$ a quantia de termos autorregressivos, $\mathrm{d}$ a quantidade de vezes que a série necessita ser diferenciada para se tornar estacionária, e q representa o número de termos de média móvel. A estrutura padrão do método ARIMA é dada conforme os seguintes conjuntos de equações [19].

$$
\begin{aligned}
& A R=c+\phi_{1} Y_{t-1}+\ldots+\phi_{p} Y_{t-p} \\
& M A=c+\theta_{1} \varepsilon_{t-1}-\ldots-\theta_{p} \varepsilon_{t-p} \\
& I_{1}=Y^{\prime}{ }_{t}=Y_{t}-Y_{t-1} \\
& I_{2}=Y^{\prime \prime}{ }_{t}=Y^{\prime}{ }_{t}-Y^{\prime}{ }_{t-1}=\left(Y_{t}-Y_{t-1}\right)-\left(Y_{t-1}-Y_{t-2}\right) \\
& A R I M A=F_{t}=A R+I+M A
\end{aligned}
$$

Em que $Y_{t}$ é a previsão no tempo $t, F_{t}$ são os valores previstos para o período $t ; c$ é a constante ou intercepto, $\phi_{p}$ é o coeficiente do fator regressivo, $\theta_{p}$ é o coeficiente do fator de média móvel, $Y_{t}^{\prime}$ são as componentes das diferenças tomadas da série e $\varepsilon_{t}$ são os erros da série. A Equação 14 representa o cálculo final do modelo, sendo composto pela soma das Equações 10, 11, 12 e 13 . 


\subsection{Inteligência Artificial}

Métodos de Inteligência Artificial como a RNA estão sendo utilizados, com mais frequência, nas previsões de demanda, pois vêm apresentando relevantes acuracidades nas análises, gerando menor erro médio absoluto $(M A E)$ e erro percentual médio absoluto (MAPE) em comparação com modelos tradicionais [20]. Técnicas de Inteligência Artificial foram e estão sendo implementadas com sucesso em áreas como biomedicina, aplicações aeroespaciais, indústria automotiva, eletrônica, indústria financeira, entre outras [21].

\subsubsection{Redes Neurais Artificiais}

As RNAs são sistemas computacionais que possuem uma concepção lógico-matemática inspirada nas estruturas de armazenamento e processamento do sistema nervoso biológico humano [22]. Contemplam uma certa quantia de neurônios artificiais, os quais são basicamente entradas e unidades de processamento do sistema, ligados por meio de pesos sinápticos [23]. O método usado para executar o processamento é denominado de algoritmo de aprendizagem, cuja função é alterar os pesos sinápticos da rede de um modo ordenado para alcançar o objetivo desejado [24].

O neurônio artificial recebe uma ou mais entradas que são adicionadas para gerar uma saída. Habitualmente, as adições de cada nó são ponderadas, sendo o resultado utilizado como entrada de uma função não linear descrito como função de ativação ou função de transferência [25]. Na Figura 1, é possível visualizar a representação de uma estrutura de RNA, em que estão contempladas a camada de entrada, a camada oculta e a camada de saída, assim como as ligações existentes entre as camadas.

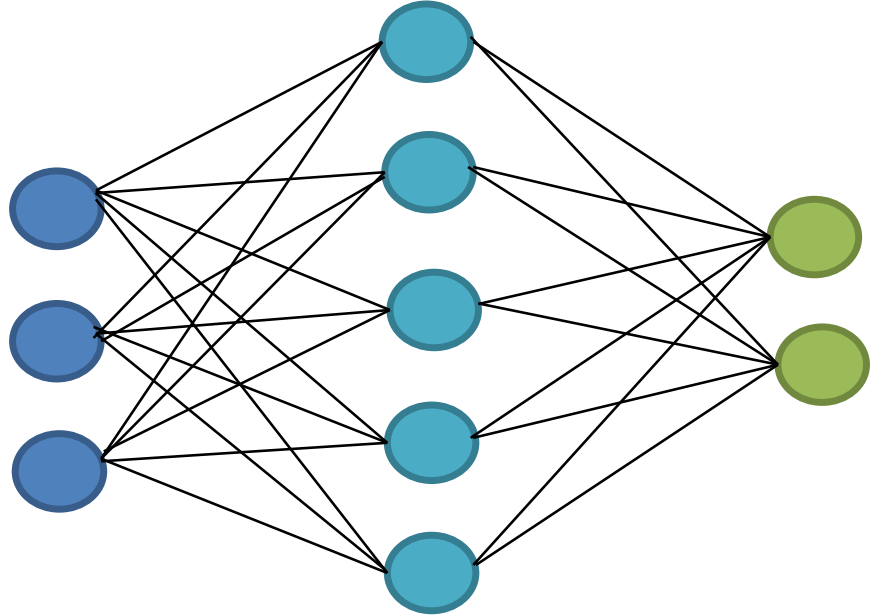

Figura 1 - Estrutura de RNA adaptado de Borsato e Corso [17].
O método RNA de previsão de demanda adequado para dados não lineares é concebido conforme a Equação 15.

$O_{k}=\psi\left(\sum_{j=1}^{q} \omega_{j k} \phi\left(\sum_{i=1}^{n} \omega_{i j} x_{i}+a_{j}\right)+b_{k}\right)$

Sendo $q$ e $n$ as quantidades de neurônios de entrada e neurônios ocultos, respectivamente; $\omega$ é o peso entre diferentes camadas; $a_{j}$ e $b_{k}$ são os limites da camada oculta e da camada de saída, respectivamente; $\phi$ e $\psi$ são as funções de motivação da camada oculta e da camada de saída, nessa ordem [26].

\subsection{Erros de Previsão}

O desempenho e a acuracidade dos modelos matemáticos apresentados podem ser medidos com base nos cálculos de erro de previsão, conforme seguem nas Equações 16 e 17.

$M A P E=\frac{1}{\mathrm{n}} \sum_{i=1}^{n} \frac{\left|e_{i}\right|}{Y_{i}} 100$

$M A E=\frac{1}{n} \sum_{i=1}^{n}\left|e_{i}\right|$

Em que MAPE é o erro percentual médio absoluto, $M A E$ é o erro médio absoluto, $e_{i}$ é a diferença do valor real com o valor previsto do i-ésimo período e $Y_{i}$ é o valor real para o respectivo período.

\section{Metodologia}

A partir da proposta do presente trabalho, fez-se necessária a realização da coleta do histórico de comercialização dos quatro principais modelos de lanternas traseiras. Após isso, executaram-se as previsões de demanda pelos modelos matemáticos apresentados na seção 2 . Os métodos utilizados para previsões de demanda no presente trabalho são técnicas quantitativas, as quais fazem uso de dados históricos e modelos matemáticos para projetar o futuro [27]. 




\subsection{Histórico de Vendas}

A empresa deste estudo possui em seu portfólio diversos itens de iluminação e elétricos, destinados principalmente para a linha automotiva pesada. Dentre os produtos existentes, as lanternas traseiras de ônibus e implementos rodoviários, certamente, são os principais destaques, por isso, foram selecionados os quatro modelos de lanternas com maior comercialização pela empresa nos últimos anos.

Visando preservar as nomenclaturas dos produtos da organização, os quatro modelos serão chamados do seguinte modo: lanterna $\mathrm{A}$, lanterna $\mathrm{B}$, lanterna $\mathrm{C}$ e lanterna $\mathrm{D}$. Como a empresa possui como característica o lançamento periódico de novos modelos de produtos, foi estipulado um período de 36 meses para coleta do histórico de vendas das lanternas A, B, C e D.

\subsection{Implementação Computacional dos Modelos Matemáticos}

Após a realização da coleta dos dados de vendas dos itens analisados, ocorreu a aplicação dos modelos matemáticos: Média Móvel Ponderada, Holt Winters Aditivo e Multiplicativo, ARIMA e RNA. O objetivo da aplicação desses métodos, de forma computacional, foi verificar os modelos que apresentaram maior acuracidade nas previsões de vendas em relação ao que realmente aconteceu. Aplicou-se, também, o método atual de previsão de demanda utilizado pela empresa do presente trabalho, o qual usa como base a média dos últimos seis meses de vendas para determinar a previsão de determinado produto; o objetivo foi de que houvesse uma comparação de acuracidade entre os métodos selecionados e o modelo atual da organização.

Para a RNA, a arquitetura da rede considera uma camada oculta. Foram testadas configurações de 10 até 100 neurônios em apenas uma camada e os algoritmos de treinamento avaliados foram Levenberg-Marquardt (LM), Bayesian Regularization (BR) e Scaled Conjugate Gradiente (SCG), tendo em vista que são os algoritmos indicados para a determinação de previsões. Os dados de entrada para aplicação do RNA foram o histórico de demanda dos 4 modelos de lanterna selecionadas. Objetivamente, deve-se encontrar a melhor configuração de RNA para cada produto. $\mathrm{O}$ algoritmo LM pode ser descrito, conforme a Equação 18.

$x_{K+1}=x_{K}-\left[J^{T} J+\mu I\right]^{-1} J^{t} e$
Em que $J$ é a matriz jacobiana que aufere e examina as primeiras derivadas dos erros da RNA, $\mu$ é a taxa de aprendizagem, $x$ é a variável que minimiza o valor da função, $e$ é o erro, I é a matriz identidade. Esse algoritmo possui maior eficiência para redes menores.

$\mathrm{O}$ algoritmo de treinamento $\mathrm{BR}$, segue por meio da Equação 19.

$p(\varnothing \mid D, M)=\frac{p(D \mid \emptyset, M) p(\emptyset \mid M)}{P(D \mid M)}$

Em que $D$ é o conjunto de dados de treinamento e $M$ é o formato funcional do modelo.

Sugere-se o uso do algoritmo SCG para questões de larga escala, sendo representado pelas Equações 20 e 21.

$s_{k}=E^{\prime \prime}\left(\theta_{k}\right) d_{k} \approx \frac{E^{\prime}\left(\theta_{t, k}\right)-E^{\prime}\left(\theta_{k}\right)}{y_{k}}$

Sujeita a:

$\alpha_{k}=\frac{-d_{k}^{T} E^{\prime}{ }_{q}\left(\theta_{1}\right)}{d_{k}^{T} S_{k}}$

$0<y_{k} \ll 1$

Em que $s_{k}$ diz respeito à informação de segunda ordem, $E^{\prime}$ e $E^{\prime \prime}$ são a primeira e segunda derivadas da função de erro referentes aos respectivos vetores de peso; $d_{k}$ é o vetor conjugado de peso temporal do k-ésimo período, em que $d_{k}^{T}$ é a transposta de $d_{k}$, e $\alpha_{k}$ é o passo do cálculo de otimização, que é realizado a cada iteração do método.

É válido salientar que existem diferentes softwares para execução dos modelos matemáticos, os quais possuem a função de otimizar o trabalho de aplicação dos métodos e evitar erros que podem acontecer ao aplicá-los de forma manual. Para o presente trabalho, utilizou-se o software IBM SPSS para os modelos matemáticos clássicos e o software Python para execução do RNA.

\subsection{Análise dos Resultados Obtidos}

Para executar uma análise correta dos resultados obtidos por meio dos métodos utilizados, fez-se necessário aplicar os conceitos de erros de previsão MAPE e MAE, em que os modelos que apresentaram os menores valores nesses quesitos, consequentemente, foram os que possuíram o maior nível de acerto, gerando valores mais próximos do real. 


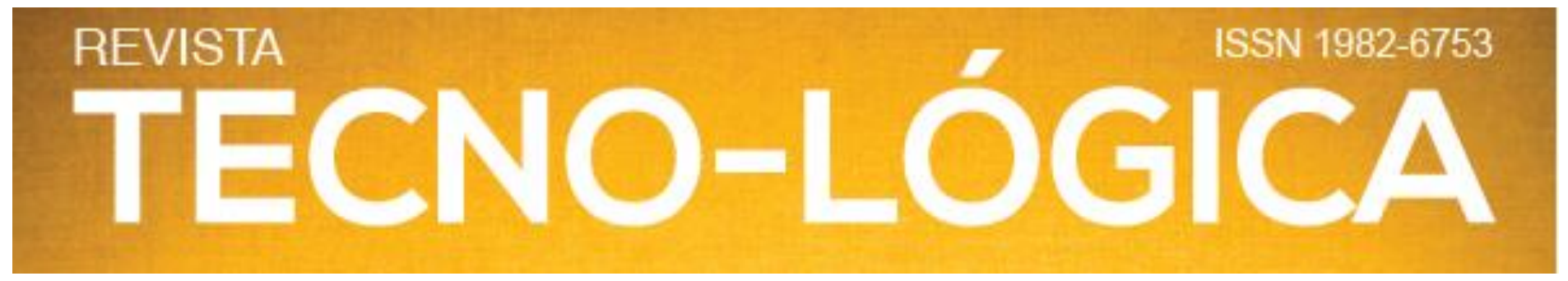

\subsection{Mensuração dos Ganhos para a Empresa e Definição do Modelo}

A verificação e a implementação do modelo matemático que resultou na maior precisão em relação aos valores reais são de suma relevância para otimização dos resultados da companhia. Por haver um ambiente de negócio competitivo e globalizado, ganhos operacionais se tornam diferenciais para as empresas.

Vale salientar também que a previsão de venda apresenta clara ligação com os níveis de estoques, em que havendo alinhamento entre ambos, haverá reduções nos custos de armazenamento, seguro, itens parados, obsoletos entre outros. Em relação à empresa do presente trabalho, outro ponto relevante é que uma previsão de demanda ineficaz e menor do que a demanda real pode acarretar a necessidade de realização de horas extras, o que, consequentemente, aumentará o custo de mão de obra, reduzindo a margem de lucro da organização.

\subsection{Mapa de Processos}

Será evidenciado um mapa de processos para facilitar o entendimento dos passos necessários para implantação do modelo indicado para a organização, conforme consta na Figura 2.

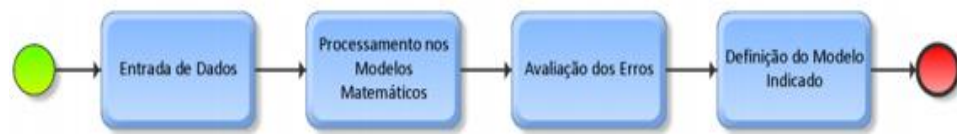

Por meio do mapa de processos, verifica-se que, de forma objetiva, há inicialmente a entrada de dados, referente ao histórico de vendas; posteriormente, é realizado o processamento dos dados nos modelos matemáticos via softwares SPSS e Python; após, há as avaliações dos erros, com base nos modelos $M A P E$ e $M A E$, e para finalizar é definido o método ou os métodos mais indicados para serem utilizados na elaboração das previsões mensais de demanda da empresa.

\section{Desenvolvimento}

Para realizar o processo de aplicação dos modelos matemáticos, inicialmente foi escolhida a gama de produtos mais relevante em termos de volume e faturamento para a empresa, com isso, determinou-se que os quatro principais modelos de lanternas traseiras da organização seriam o objeto de estudo deste trabalho. A coleta dos dados de comercialização dos produtos ocorreu por meio do software Power BI que a empresa possui, o qual contempla informações de preços de venda, volumes comercializados, faturamentos por cliente ou segmento etc., sendo possível visualizar essas informações desde o ano de 2013.

Pelo fato de a empresa possuir um viés inovador, característica necessária, também, para obtenção de sucesso no mercado em que atua, os produtos são renovados, em média, a cada 3 a 4 anos; diante disso, foi possível coletar o histórico de vendas em um período de 36 meses. Desse modo, o intervalo de coleta dos dados de vendas ocorreu entre o mês de maio de 2017 e abril de 2020, podendo ser observados na Figura 3.

Figura 2 - Mapa de Processos.

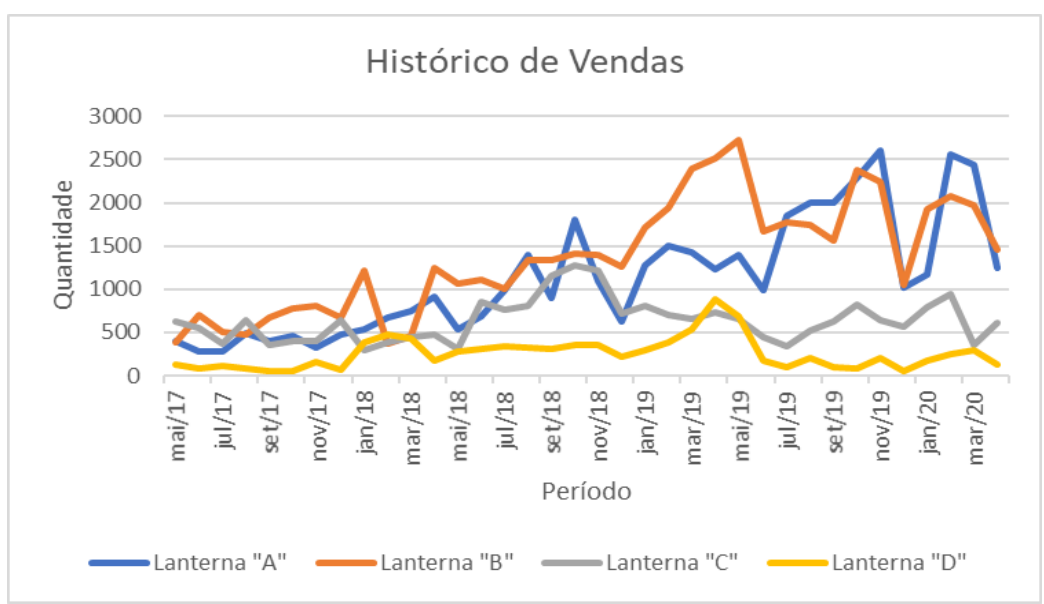

Figura 3 - Histórico de vendas. 


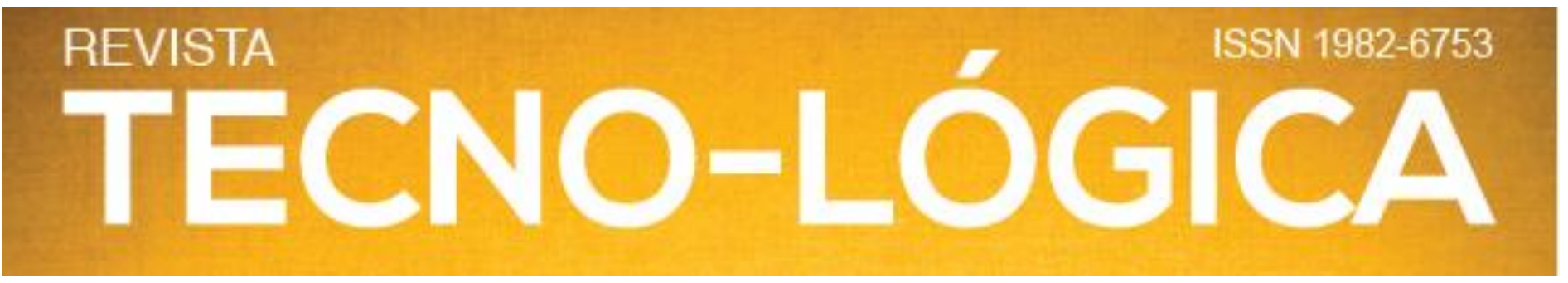

Os modelos matemáticos de séries temporais Média Móvel Ponderada, HWM, HMA e ARIMA foram executados por meio do software SPSS, sendo gerada a previsão dos 36 meses analisados para cada método. O modelo de Inteligência Artificial RNA foi concebido via software Python, em que foram originadas 273 previsões de 34 meses para cada tipo de lanterna traseira, tendo em vista que se trabalhou com configurações de 10 até 100 neurônios para cada algoritmo de treinamento (LM, BR e SCG). A configuração do RNA no Python se deu considerando $70 \%$ treino, $15 \%$ validação, $15 \%$ teste e delay igual a 2 .

Posteriormente à obtenção das previsões de demanda, utilizou-se o software Microsoft Excel para cálculos dos métodos de erros $M A P E$ e $M A E$, em que foi possível constatar quais os modelos matemáticos apresentaram maior acuracidade. As Tabelas 1 e 2 apresentam os valores de MAPE e MAE originados.

Analisando os dados da Tabela 1, verificou-se que o método RNA é o de maior acuracidade para todos os modelos de lanternas. Para a lanterna A, a otimização de RNA que gerou 10,53\% de erro $M A P E$ foi com 21 neurônios e algoritmo de treinamento BR. Para a lanterna B, a configuração otimizada com 26 neurônios e algoritmo de treinamento LM resultou em 8,04\% de MAPE. Já para o produto $\mathrm{C}$, o modelo de RNA com maior acuracidade foi com 85 neurônios e algoritmo de treinamento LM, resultando em $11,72 \%$ de erro percentual médio absoluto, e, em relação à lanterna $\mathrm{D}$, a otimização que obteve $22,53 \%$ foi contemplando 50 neurônios e algoritmo de treinamento BR.

Na Figura 4, são demonstradas as demandas reais de cada lanterna para o período analisado (maio de 2017 a abril de 2020), as previsões geradas mensalmente pelas configurações de RNA de maior acurácia e pelo modelo de previsão da empresa, para que fosse possível constatar visualmente a diferença relevante de precisão.

Tabela 1 - Erro Percentual Médio Absoluto (MAPE) $M A P E$

\begin{tabular}{ccccc}
\hline \multirow{2}{*}{ Método } & Lanterna & Lanterna & Lanterna & Lanterna \\
& A & B & C & D \\
\hline RNA & $10,53 \%$ & $8,04 \%$ & $11,72 \%$ & $22,53 \%$ \\
HWM & $35,00 \%$ & $37,00 \%$ & $33,33 \%$ & $64,02 \%$ \\
HWA & $30,80 \%$ & $26,84 \%$ & $26,42 \%$ & $40,73 \%$ \\
ARIMA & $26,88 \%$ & $25,70 \%$ & $33,39 \%$ & $76,96 \%$ \\
MMP & $32,00 \%$ & $31,00 \%$ & $34,00 \%$ & $53,00 \%$ \\
MÉTODO & $30,79 \%$ & $28,90 \%$ & $34,52 \%$ & $76,75 \%$ \\
EMPRESA & & & & \\
\hline
\end{tabular}

Tabela 2 - Erro Médio Absoluto (MAE)

\section{$M A E$}

\begin{tabular}{ccccc}
\hline \multirow{2}{*}{ Método } & Lanterna & Lanterna & Lanterna & Lanterna \\
& A & B & C & D \\
\hline RNA & 91 & 94 & 73 & 27 \\
HWM & 1138 & 1370 & 205 & 127 \\
HWA & 239 & 263 & 142 & 80 \\
ARIMA & 285 & 273 & 187 & 126 \\
MMP & 301 & 307 & 180 & 110 \\
MÉTODO & 395 & 388 & 221 & 147 \\
EMPRESA & & & & \\
\hline
\end{tabular}

Em relação a Tabela 2, também se constatou que o método de inteligência artificial RNA é o de menor erro $M A E$ para os 4 modelos de produtos. A configuração com 26 neurônios e algoritmo de treinamento BR resultou no $M A E$ de 91 unidades para a lanterna A e 94 peças para a lanterna B; a otimização com 40 neurônios e algoritmo de treinamento BR gerou um erro médio absoluto de 73 unidades para a lanterna C, e, para o produto D, a configuração otimizada com 50 neurônios e algoritmo de treinamento BR gerou um erro $M A E$ de 27 unidades.

São demonstrados na Figura 5 os volumes de comercialização reais das lanternas, suas previsões pelo método atual da organização e as demandas geradas pelas configurações de RNA otimizadas no quesito $M A E$. Assim como na Figura 4, é possível visualizar na Figura 5 que as otimizações de RNA conseguem acompanhar, de forma eficaz, as sazonalidades presentes nas demandas dos quatro produtos em questão.

Analisando os resultados de aplicações dos métodos, é possível constatar que não necessariamente a configuração de RNA com maior acurácia para o $M A P E$ é o método mais eficaz também para o $M A E$. Essa situação é normal, pois o $M A P E$ é medido percentualmente e o $M A E$ é mensurado em unidades. Para este estudo em específico, sugere-se optar pelos modelos de maior eficácia no erro $M A E$, pois os percentuais de erro gerados pelas melhores configurações de RNA no $M A P E$, em média, irão gerar um maior número de peças em relação às configurações encontradas no $M A E$. 


\section{REVISTA}

ISSN $1982-6753$
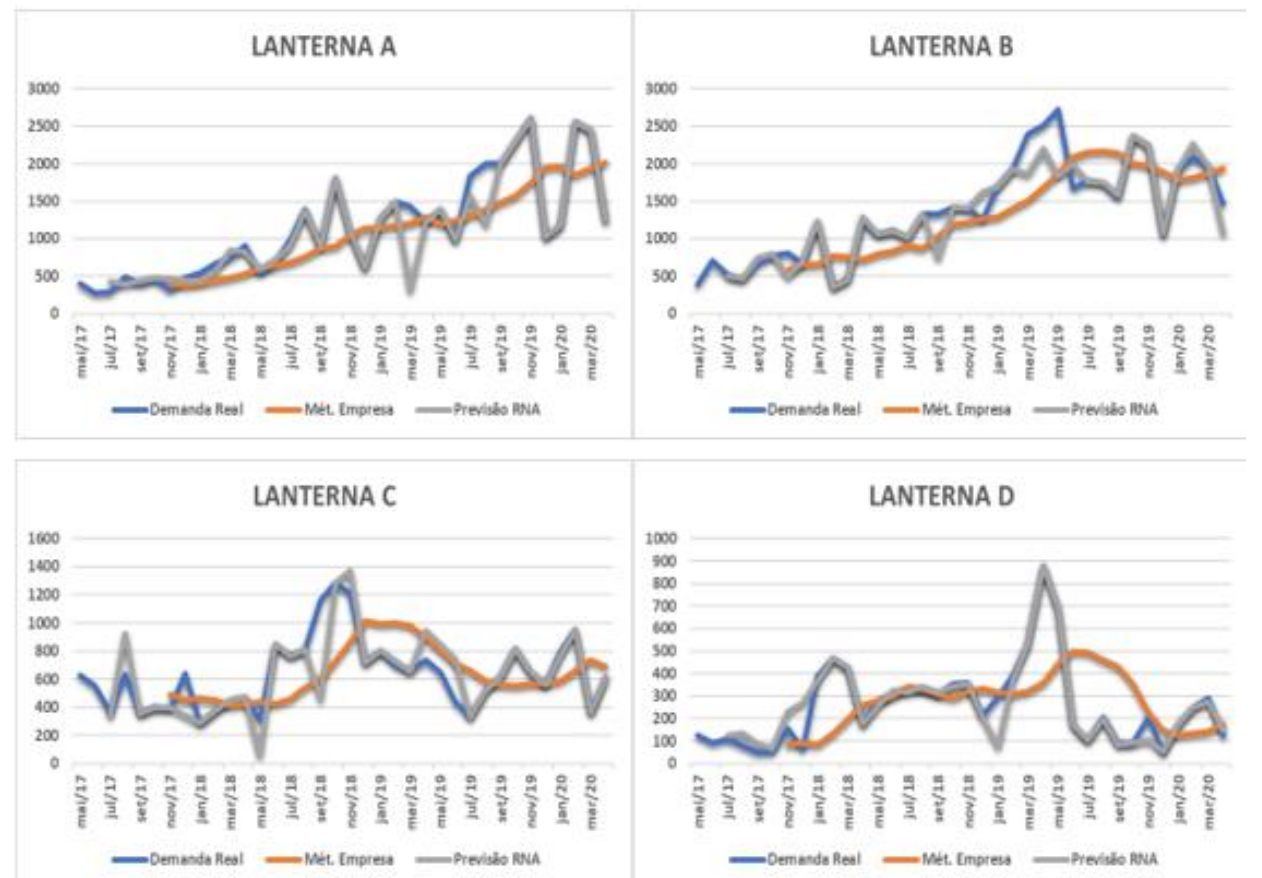

Figura 4 - Demanda Real x Método da Empresa x Previsão Modelo Matemático.


Figura 5 - Demanda Real x Método da Empresa x Previsão Modelo Matemático. 


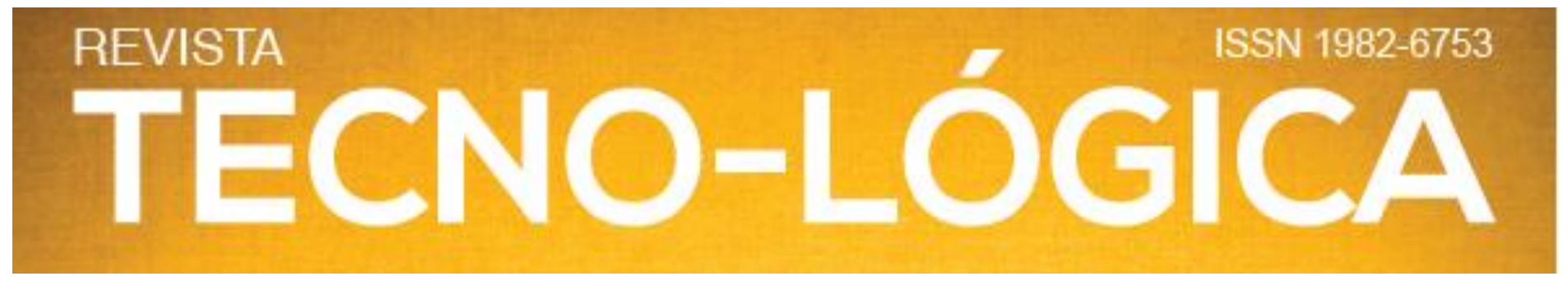

Ao comparar as eficácias dos métodos utilizados, constata-se que a RNA otimizada apresentou, em média, erros de previsão de 3,25 vezes (para o $M A P E$ ) e de 4 vezes (para o $M A E$ ) menor em relação ao método atual da empresa.
Como sugestão para implementação da RNA no escopo de trabalho da empresa analisada, foi realizado o fluxograma constante na Figura 6, em que são mencionadas as etapas para geração da previsão de demanda e, como conclusão, a alimentação das informações das previsões à área de Planejamento e Controle de Produção da Organização.



Figura 6 - Implementação do Modelo Matemático RNA na empresa.

\section{Considerações Finais}

Este artigo visou implementar modelos matemáticos de séries temporais e inteligência artificial para determinar a previsão de demanda dos principais produtos de uma empresa fabricante de sistemas de iluminação automotivo. Foram selecionados quatro modelos de lanternas e coletado o seu histórico de comercialização em um período de 36 meses para que fosse utilizado como base de dados para aplicação dos métodos.

Por meio da aplicação dos conceitos de erros de previsão, foi possível comparar a eficácia dos modelos de séries temporais, RNA e método atual da empresa. Visando otimizar a RNA, foram testados diferentes configurações e algoritmos de treinamento. Ficou evidenciado que a RNA otimizada é o mais indicado para a organização, tendo em vista que apresentou maior acuracidade na previsão dos quatro produtos analisados; ao mesmo tempo, também se constatou que uma RNA não configurada propriamente pode gerar elevados erros de previsão.
Vale ressaltar que os métodos de séries temporais HWA, ARIMA e MMP apresentaram, também, erros de previsão satisfatórios, principalmente em relação ao $M A E$. Analisando-se sob a ótica do erro médio absoluto, apenas o modelo HWM não obteve resultados positivos em comparação ao método atual da empresa.

Ao analisar as configurações da RNA que resultaram na maior acuracidade, verifica-se que o algoritmo de treinamento BR é o que apareceu com mais frequência, e, posteriormente o algoritmo de treinamento LM. Por meio dos gráficos apresentados na seção 4, foi possível visualizar a assertividade da RNA otimizada ao longo do tempo, em que ela conseguiu acompanhar as sazonalidades existentes, resultando em erros de previsão menores na ordem de 3,25 a 4 vezes em relação ao modelo atual da organização.

Como proposta para continuidade e aprimoramento dos resultados obtidos neste trabalho, é relevante que haja atualizações dos dados mensalmente e novas avaliações dos modelos, uma vez que o comportamento dos dados pode variar ao longo do tempo. 


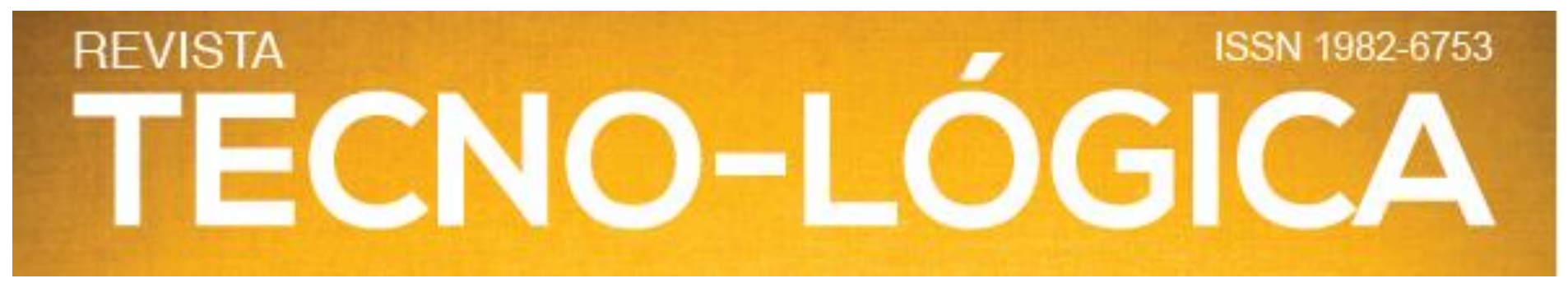

Sugere-se realizar alterações no treinamento da RNA, como, por exemplo, elevar a quantia de dados de treinamento e testagem com outros parâmetros. Também indica-se utilizar mais modelos de aprendizagem de máquina, como o algoritmo evolutivo usado para solucionar questões de otimização multiobjetivo (NSGA II).

\section{FORECAST MODELS AND ARTIFICIAL INTELLIGENCE APPLICATION TO EVALUATE DEMAND IN THE AUTOMOTIVE LIGHTING SYSTEMS SEGMENT}

ABSTRACT: The Market competition encourages the companies to seek innovation in order to stand out, bringing value to the segment they operate in. This strong competition creates a need for organizations to look for ways to reduce costs and streamline processes; the accuracy on the demand forecasting is an essential factor to improve productivity, stock management and lead time reduction, contributing to the company's results. This paper's goal is to use mathematical models from time series and artificial intelligence to check which method is the most accurate in forecasting the demand of a lighting automotive company. The Artificial Neural Networks (RNA) method was optimized through settings considering the number of neurons and different training algorithms to find the most accurate models. Through the application of the MAPE and MAE forecasting errors, the conclusion was that some RNA settings are the most accurate methods to make predictions of the analyzed products, and that, in average, the optimized RNA forecasting errors are 3,25 times (for MAPE) and 4 times (for MAE) lower than the actual company's method.

Keywords: Demand forecasting. Stock management. Artificial Neural Networks.

\section{Referências}

[1] BOTELHO, D.; GUISSONI, L. Varejo: competividade e inovação. Revista de Administração de Empresas, São Paulo, v. 56, n. 06, p. 596-599, nov./dez. 2016. https://doi.org/10.1590/s0034-759020160602. Disponível em: http://www.scielo.br/scielo.php?script=sci_arttext\&pid=S003475902016000600596\&lng=pt\&tlng=pt. Acesso em: 16 mar. 2020.

[2] MANCUSO, A. C. B.; WERNER, L. Estudo dos métodos de previsão de demanda aplicado em uma empresa de auditorias médicas. Revista Ingeniería Industrial, Concepción, Chile, v. 01, n. 13, p. 99-111, 2014. Disponível em: http://revistas.ubiobio.cl/index.php/RI/article/view/6/3251. Acesso em: $18 \mathrm{mar}$ 2020.

[3] HAYKIN, Simon. Redes Neurais: Princípios e Práticas. BOOKMAN, 2 ed, São Paulo, p. 28, 2007. ISBN 0-13-273350-1. Disponível em: https://soartigos.files.wordpress.com/2015/07/redes_neurais_simon_haykin.pdf. Acesso em: 3 jul. 2021.

[4] TRATAR, L. Improved holt-winters method: a case of overnight stays of tourists in Republic Of Slovenia. Economic and Business Review, Ljubljana, v. 16, n. $01, \quad$ p. 5-17, 2013. Disponível em: https://ojs.ebrjournal.net/ojs/index.php/ebr/article/view/266. Acesso em: 21 mar. 2020 .

[5] VIJAIA, P.; SIVAKUMAR, B. Performance comparison of techniques for water demand forecasting. Elsevier, Coimbatore, v. 143, p. 258-266, 2018. https://doi.org/10.1016/j.procs.2018.10.394. Disponível em: https://www.sciencedirect.com/science/article/pii/S187705091832091X. Acesso em: 21 mar. 2020.

[6] CAMElO, H. N.; LUCIO, P. S.; LEAL JÚNIOR, J. V. Modelagem da velocidade do vento usando metodologias ARIMA, Holt-Winters e RNA na previsão de geração eólica no nordeste brasileiro. Revista Brasileira de Climatologia, Curitiba, v. 21, p. 449-466, jul./dez. 2017. http://dx.doi.org/10.5380/abclima.v21i0.48565. Disponível em: https://revistas.ufpr.br/revistaabclima/article/view/48565/34043. Acesso em: 18 mar. 2020.

[7] MANCUSO, A. C. B.; WERNER, L. Estudo dos métodos de previsão de demanda aplicado em uma empresa de auditorias médicas. Revista Ingeniería Industrial, Concepción, Chile, v. 01, n. 13, p. 99-111, 2014. Disponível em: http://revistas.ubiobio.cl/index.php/RI/article/view/6/3251. Acesso em: $18 \mathrm{mar}$. 2020

[8] SILVA, et al. Stock control: a study on stock management efficiency in a wholesale distributor in Divinópolis-MG. Research, Society and Development, v. 7, n. 5, p. 01-16, jan. 2018. http://dx.doi.org/10.17648/rsd-v7i5.247. Disponível em: https://rsd.unifei.edu.br/index.php/rsd/article/view/247/177. Acesso em: 07 abr. 2020.

[9] PINTO, et al. Gestão de Estoque e Lean Manufacturing: estudo de caso em uma empresa metalúrgica. Revista Administração em Diálogo - RAD, v. 15, p. 111-138, n. 1, fev. 2013. https://doi.org/10.20946/rad.v15i1.12095. Disponível em: https://revistas.pucsp.br/rad/article/view/12095/16636. Acesso em: 07 abr. 2020.

[10] SHARMA, S.; KOCHAK, A. Demand forecasting using neural network for supply chain management. Int. J. Mech. Eng. \& Rob. Res, v. 4, n. 1, p. 96-104, jan. 2015. Disponível em: http://www.ijmerr.com/v4n1/ijmerr_v4n1_10.pdf. Acesso em: 08 abr. 2020

[11] ZAN, G.; SELLITTO, M. Técnicas de previsão de demanda: um estudo de caso triplo com dados de venda de materiais eletromecânicos. GEPROS, v. 4, n. 2 , p. 95-106. Disponível em: https://revista.feb.unesp.br/index.php/gepros/article/viewFile/171/119. Acesso em: 08 abr. 2020

[12] MANCUSO, A. C. B.; WERNER, L. Estudo dos métodos de previsão de demanda aplicado em uma empresa de auditorias médicas. Revista Ingeniería Industrial, Concepción, Chile, v. 01, n. 13, p. 99-111, 2014. Disponível em: http://revistas.ubiobio.cl/index.php/RI/article/view/6/3251. Acesso em: 18 mar. 2020 .

[13] NUGRAHANI, T. A.; ADI, K.; SUSENO, J. E. Information System Prediction With Weighted Moving Average (WMA) Method And Optimization Distribution Using Vehicles Routing Problem (VRP) Model for Batik Product. E3s Web Of Conferences, Indonésia, v. 73, p. 13004-13010, dez. 2018. 10.1051/e3sconf/20187313004. Disponível em: https://www.e3s-conferences.org/. Acesso em: 15 abr. 2020. 


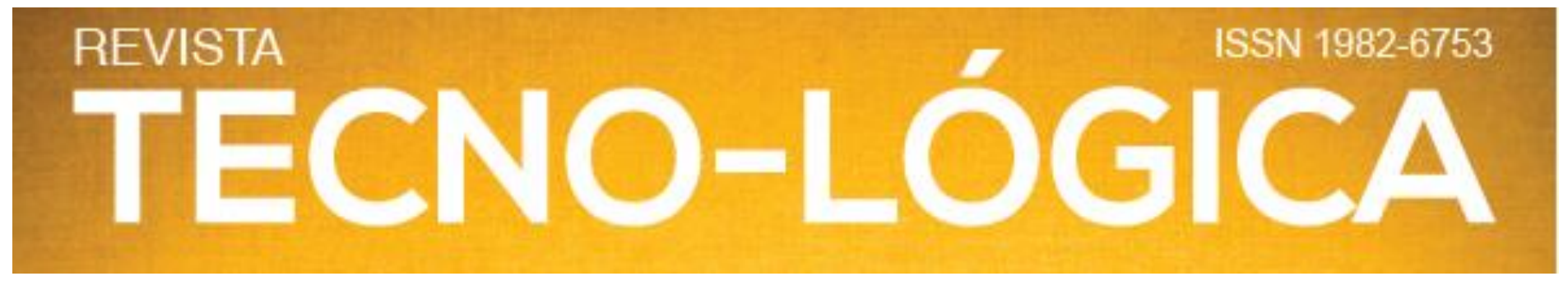

[14] BOORANAWONG, A.; BOORANAWONG, T. Double exponential smoothing and Holt-Winters methods with optimal initial values and weighting factors for forecasting lime, Thai chili and lemongrass prices in Thailand. EASR, Thailand, v. 45, n. 01, p. 32-38, mar. 2018. 10.14456/easr.2018.5. Disponível em: https://ph01.tci-thaijo.org/index.php/easr/article/view/73088. Acesso em: 24 mar. 2020.

[15] FERRO, W.; LIMA, J.; TRENTIN, M. Combinações de Métodos Quantitativos na Previsão de Demanda de Vendas de Eletrodomésticos. GEPROS, Bauru, v. 14, n. 05, p. 67-88, 2019. https://doi.org/10.15675/gepros.v14i5.2371. Disponível https://revista.feb.unesp.br/index.php/gepros/article/view/2371/pdf. Acesso em: 24 mar. 2020.

[17] BORSATO, R.; CORSO, L. Aplicação de Inteligência Artificial e ARIMA na Previsão de Demanda no setor metal mecânico. Scientia Cum Industria, v. 07, n. 02, p. 165-176, jan. 2019. 10.18226/23185279.v7iss2p165. Disponível em: http://www.ucs.br/etc/revistas/index.php/scientiacumindustria/article/view/7741. Acesso em: 26 mar. 2020.

[18] LIMA, J.; CASTRO, L.; CARTAXO, G. Aplicação do Modelo SARIMA na Previsão de Demanda no Setor Calçadista. ID Online, Cariri, v. 13, n. 46, p. 892913, fev. 2019. 10.14295/idonline.v13i46.1875. Disponível em: https://idonline.emnuvens.com.br/id/article/view/1875. Acesso em: 27 mar. 2020.

[19] LIMA, J.; CASTRO, L.; CARTAXO, G. Aplicação do Modelo SARIMA na Previsão de Demanda no Setor Calçadista. ID Online, Cariri, v. 13, n. 46, p. 892913, fev. 2019. 10.14295/idonline.v13i46.1875. Disponível em: https://idonline.emnuvens.com.br/id/article/view/1875. Acesso em: 27 mar. 2020.

[20] HUANG, J.; TANG, Y.; CHEN, S. Energy demand forecasting: combining cointegration analysis and artificial intelligence algorithm. Hindawi, v. 2018, p. 113. https://doi.org/10.1155/2018/5194810. Disponível em: https://www.hindawi.com/journals/mpe/2018/5194810/\#copyright. Acesso em: 06 abr. 2020.

[21] RAZA, Muhammad Qamar; KHOSRAVI, Abbas. A review on artificial intelligence based load demand forecasting techniques for smart grid and buildings. Renewable and Sustainable Energy Reviews, v. 50, p. 1352-1372. doi:10.1016/j.rser.2015.04.065. Disponível em: https://www.journals.elsevier.com/renewable-and-sustainable-energy-reviews. Acesso em: 09 abr. 2020.

[22] BATISTA, et al. Artificial Neural Networks And Medical Education. Rev. bras. educ. med., Rio de Janeiro, v. 38, n. 4, p. 548-556, dez. 2014. https://doi.org/10.1590/S0100-55022014000400017. Disponível em: http://www.scielo.br/scielo.php?frbrVersion=2\&script=sci_arttext\&pid=S010055022014000400017\&lng=en\&tlng=en. Acesso em: 04 abr. 2020.

[23] MACHADO, W.; JUNIOR, E. Redes Neurais Artificiais Aplicadas Na Previsão do VTEC no Brasil. Bol. Ciênc. Geod., v. 19, n. 02, p. 227-246, jun. 2013. https://doi.org/10.1590/S1982-21702013000200005. Disponível em: http://www.scielo.br/scielo.php?script=sci_arttext\&pid=S1982-

21702013000200005. Acesso em: 29 mar. 2020.

[24] HAYKIN, Simon. Redes Neurais: Princípios e Práticas. BOOKMAN, 2 ed, São Paulo, p. 28, 2007. ISBN 0-13-273350-1. Disponível em: https://soartigos.files.wordpress.com/2015/07/redes_neurais_simon_haykin.pdf. Acesso em: 3 jul. 2021

[25] MEDEIROS, et al. Previsão de demanda a médio prazo aplicada em dados reais do sistema de distribuição: uma comparação entre RNA e Lógica Fuzzy. Principia, [S.1.], n. 31, p. 75-85, dez. 2016. http://dx.doi.org/10.18265/151703062015v1n31p75-85. https://periodicos.ifpb.edu.br/index.php/principia/article/view/511. Acesso em: 29 mar. 2020.

[26] HUAI, et al. Deterministic wind energy forecasting: A review of intelligent predictors and auxiliary methods. Energy Conversion and Management, v. 195, p. 328-345, set. 2019. https://doi.org/10.1016/j.enconman.2019.05.020. Disponível em: https://www.sciencedirect.com/science/article/pii/S0196890419305655. Acesso em: 29 mar. 2020.

[27] CRUZ, A. B. Comparação entre modelos de previsão de demanda: estudo de caso de um restaurante de comida japonesa. REMAT, Caxias do Sul, v. 2, n. 02, p. 180-197, 2016. https://doi.org/10.35819/remat2016v2i2id1293. Disponível em: https://periodicos.ifrs.edu.br/index.php/REMAT/article/view/1293/1312. Acesso em: 24 mar. 2020. 